\title{
O fim das favelas? Planejamento, participação e remoção de famílias em Belo Horizonte
}

\author{
The end of slums? Planning, participation \\ and removal of families in Belo Horizonte
}

Clarice de Assis Libânio

\section{Resumo}

Ao contrário do observado em várias partes do mundo, Belo Horizonte apresentou decréscimo no número de favelas e de seus moradores, indicando intenso processo de remoção de famílias e desfavelização, levado a cabo pelo próprio Estado. Este artigo foca as políticas públicas e o planejamento para as favelas em Belo Horizonte nos últimos anos, apontando inflexão nas práticas governamentais nas favelas, no sentido inverso das lutas dos movimentos sociais e das conquistas históricas de suas populações: de um lado, na garantia do direito de permanência das famílias no local e, de outro, no direito de participação cidadã. Se houve avanços na consolidação urbanística das favelas e nos serviços públicos, a apropriação e o uso do espaço urbano como direito avançaram pouco, apesar da Constituição Federal e do Estatuto da Cidade garantirem o direito à moradia como um dos direitos fundamentais, buscando-se a efetivação da função social da terra urbana.

Palavras-chave: Belo Horizonte; favelas; remoções; Vila Viva; gentrificação; direito à moradia; participação cidadã.

\begin{abstract}
Unlike what has been observed in various parts of the world, the city of Belo Horizonte has presented a decrease in the number of slums and their residents, which indicates an intense process of removal of families, conducted by the State itself. The article focuses on public policies and planning for slums in Belo Horizonte in recent years, showing that the governmental practices in slums have moved in the opposite direction of the social movements' struggles and of the historical achievements of their populations: first, regarding the guarantee of the families' right to remain at the place and, second, concerning the right of citizen participation. If progress has been made in the urban consolidation of slums and public services, what least advanced was the appropriation and use of urban space as a right, although the Federal Constitution and the City Statute guarantee the right to housing as a fundamental right, in an attempt to fulfil the social function of urban land.
\end{abstract}

Keywords: Belo Horizonte; slums, removals; Vila Viva; gentrification; housing rights; citizen participation. 
A segregação urbana não é um status quo inalterável, mas sim uma guerra social incessante, na qual o Estado intervém regularmente em nome do "progresso"', do "embelezamento" e até da "justiça social para os pobres", para redesenhar as fronteiras espaciais em prol de proprietários de terrenos, investidores estrangeiros, a elite com suas casas próprias e trabalhadores de classe média. (Davis, 2006, p. 105)

\section{Introdução}

0 artigo que ora se apresenta pretende refletir a respeito do direito à cidade e à participação cidadã, focando políticas públicas e ações de planejamento para as áreas de favelas ${ }^{1}$ na cidade de Belo Horizonte, em especial nos últimos anos.

A cidade de Belo Horizonte, capital do estado de Minas Gerais, conta com cerca de 2,5 milhões de habitantes (IBGE - Censo 2010 e Contagem da população 2015), sendo a sexta em população do País. Em sua Região Metropolitana residem 5,5 milhões de pessoas, a terceira maior do País.

Fundada em 1897, foi a primeira cidade planificada do Brasil. Entretanto, junto com a cidade, nasceram as favelas, visto que, no plano original da nova capital, não havia setores destinados à residência dos trabalhadores que a construíram. Com crescimento rápido e desordenado, em 1912 (apenas 15 anos depois da fundação) já havia $60 \%$ da população vivendo em zonas denominadas rurais ou suburbanas. Em 1955, eram 36,4 mil pessoas nas favelas, número este que chegou a 120 mil em 1965.

Nos dias atuais, a Capital conta com mais de 450 mil pessoas vivendo nas favelas, como se verá a seguir, ${ }^{2}$ em mais de 200 áreas de ocupação irregular. ${ }^{3}$ Além disso, transborda para os 33 municípios metropolitanos, uma vez que não tem mais zonas de expansão ou terrenos a baixo custo para habitação popular, criando e adensando cidades-dormitório em seu entorno, formadas por populações pobres.

Em linhas gerais, o texto defende que tem havido uma inflexão nas práticas governamentais nesses territórios, caminhando no sentido inverso das lutas dos movimentos sociais e das conquistas históricas das populações aí residentes. Essa inflexão tem duplo caráter, notadamente no que se refere aos aspectos de garantia do direito de permanência das famílias no local e do direito de participação nas decisões a elas afetas.

Nesse sentido, percebe-se, na cidade, a configuração de um novo marco do planejamento urbano para as favelas, com o uso crescente das práticas de remoção de famílias para fins de obras públicas, tendo como consequências o agravamento dos processos de gentrificação e uma série de impactos de ordem social, urbana e econômica.

Após apresentar as principais diretrizes e discutir as trajetórias das políticas públicas para as favelas em Belo Horizonte, o artigo traz um breve olhar sobre o Programa Vila Viva e seu significado no contexto da cidade. 
Considerado como um dos projetos sustentadores da Prefeitura de Belo Horizonte - PBH, prevê em seu escopo a remoção de quase seis mil famílias entre 2014 e 2017, atingindo os principais aglomerados da cidade.

Com base no exposto, vale perguntar: no contexto da cidade empreendedora, estado e mercado têm se aliado contra a população e os cidadãos? Como as políticas públicas contribuem nesse sentido? 0 objetivo implícito seria o "fim" das favelas e de sua particular forma de ocupação do espaço, jogando os pobres cada vez mais para a periferia?

\section{As políticas públicas e as favelas: trajetórias e experiências}

0 crescimento das favelas está historicamente ligado ao processo de urbanização, acelerado no Brasil a partir das décadas de 1960-1970.

Entretanto, vale lembrar que seu surgimento remonta ao final do século XIX, tanto no Rio de Janeiro 4 quanto em Belo Horizonte, onde as primeiras áreas faveladas se constituíram desde a construção da nova Capital.

Em períodos mais recentes, a literatura aponta o agravamento da questão habitacional no País, muitas vezes impactada pelas próprias políticas urbanas e suas prioridades ao longo do tempo. ${ }^{5}$ De acordo com Maricato (2011, p. 76), "as cidades estão piorando e muito", já que as políticas de incremento do consumo e de aceleração do crescimento (desordenado) têm trazido graves crises urbanas, relacionadas à mobilidade, à poluição ambiental, à ampliação da segregação, ao aumento da violência e a riscos associados às mudanças climáticas.

No caso específico das favelas, em pouco mais de um século de sua existência, é possível perceber que têm sido objeto de políticas públicas que oscilam entre dois polos e suas variantes: de um lado, concepções e propostas que têm como foco e prioridade a retirada das famílias; e, de outro, projetos de melhorias das comunidades, garantida sua permanência no mesmo local.

Seguindo esse movimento pendular, em Belo Horizonte pode-se afirmar que até 1980 predominou uma visão "remocionista", tendo o desfavelamento como seu principal método de ação nesses territórios. Nesse escopo, cita-se a criação do Departamento de Bairros Populares - DBP, em $1955,{ }^{6}$ e da Coordenadoria de Habitação de Interesse Social de Belo Horizonte - Chisbel, em 1971.7 Ambos os órgãos entendiam as ocupações como problema de polícia e tinham na remoção de famílias seu foco, buscando liberar as áreas centrais das chamadas invasões, enviando para longe do centro as populações que ali residiam.

Nas diversas administrações que se seguiram, entre 1971 e 1982 foram removidas quase 10 mil famílias assentadas em 422 áreas, totalizando cerca de 68 mil pessoas afetadas (Lopes, 2010). Quando havia alguma compensação, predominavam as indenizações em dinheiro, em valores irrisórios, o que acabava por contribuir para o adensamento de outras favelas já existentes ou para o surgimento de novas invasões.

A década de 1980 mudou a visão sobre as favelas, principalmente pela ação dos movimentos sociais. Importante, nesse sentido, foi a invasão da Prefeitura (1981) pelo movimento 
de favelados, para que as favelas fossem reconhecidas. A partir desse momento, é possível afirmar que a "era da remoção" foi substituída (temporariamente) pela "era da urbanização", com a implantação do Programa de Desenvolvimento de Comunidades - Prodecom, em 1981 (GTZ/Seplan); da Lei do Programa Municipal de Regularização de Favelas - Profavela, em 1983, ${ }^{8}$ e na criação da Companhia Urbanizadora de Belo Horizonte - Urbel em $1986 .{ }^{9}$

A visão dominante, bem como a orientação dentro do poder público, passa a ser a da necessidade de se reconhecer esses territórios como parte integrante da cidade e que deveriam ser consolidados do ponto de vista tanto urbanístico quanto jurídico. De fato, é possível afirmar que houve avanços significativos nesse período, com a mudança de paradigmas nas políticas públicas para favelas. Ao contrário das visões remocionistas, higienistas e civilizatórias até então em voga, construiu-se, com o apoio da Igreja e mobilização dos movimentos sociais, uma visão da importância de se manter as famílias em seu local de moradia, garantindo o direito de permanência (regularização fundiária) e melhorando as condições de vida nesses locais (urbanização).

A partir do início da década de 1990, ${ }^{10}$ a Urbel concentrou sua ação apenas na urbanização de favelas, diminuindo drasticamente sua atuação na legalização de terras, uma vez que não restavam mais terrenos públicos municipais para regularizar. Assim sendo, no cômputo geral, é possível afirmar que, em Belo Horizonte, avançou-se mais na urbanização do que na regularização fundiária, visto que havia poucas áreas de domínio da Prefeitura de Belo Horizonte, não se implantando um instrumento eficaz para a regularização de áreas de particulares ou mesmo terras devolutas de propriedade da União e do Estado.

Durante os anos de 1990 e 2000, viu-se o processo participativo se fortalecer com a Constituição Federal, o Estatuto das Cidades e os novos instrumentos de planejamento urbano. Aprofundaram-se as ações em favelas, em direção a uma visão do direito à cidade e da necessidade de se trabalhar de maneira integrada as intervenções no território, casando urbanização, regularização fundiária, serviços públicos, programas de acesso a trabalho e renda e fortalecimento da organização e da participação comunitária em todo o processo. Essa visão "estrutural" teve seu marco inicial com o Programa Alvorada (PBH/Urbel/AVSI) ${ }^{11}$ e culminou na obrigatoriedade de elaboração dos Planos Globais Específicos - PGE antes da realização de qualquer intervenção em áreas decretadas como Zonas de Especial Interesse Social - Zeis 1 .

Apesar de seus avanços, a chamada intervenção estrutural foi atropelada por uma série de fatores que ainda merecem maior aprofundamento e análise. Entre estes se pode citar: falta de agilidade na implementação das ações, especialmente considerando que cada uma das obras precisava ser aprovada no orçamento participativo, em anos sucessivos; pequena escala para atendimento ao grande número de favelas existentes na cidade; falta de recursos ou de vontade política das diversas administrações que se sucederam à frente da Prefeitura e da Urbel nesse período. Como resultado, pode-se perceber a fragmentação das intervenções, o descompasso entre o que foi previsto e o que foi realizado, o desvio progressivo das concepções originais dos PGEs e, em alguns casos, até mesmo a completa desconsideração das 
demandas da população residente em cada área trabalhada.

Infelizmente, nos últimos 10 ou 15 anos, $^{12}$ a cidade tem visto o retrocesso da atenção integrada e participativa nas favelas. A prática do desfavelamento, ainda que não assumida como filosofia e prioridade, vem sendo realizada com grande frequência pelo poder público na capital e região metropolitana. Inicialmente essas práticas foram incrementadas com a criação do Programa de Reassentamento de Famílias em Decorrência de Obras Públicas ou Vítimas de Calamidades - Proas, estendendo-se para as obras de implantação das propostas dos novos PGEs, que acabam por trazer de volta o fantasma da Chisbel e do desfavelamento.

Vêm sendo executadas várias intervenções com significativo número de remoções, que privilegiam as grandes obras, especialmente para implantação de eixos viários de integração urbana. ${ }^{13}$ É importante perceber que as ações de remoção de famílias na cidade parecem não ser contingentes, mas cada dia mais indicam a tendência e o pensamento que vem norteando as políticas urbanas. Entre 1995 e 2005, foram realizadas 2.866 remoções em virtude de obras públicas na cidade, ao passo que somente no ano de 2006 esse número foi de 2.133 famílias removidas (Lopes, 2010). ${ }^{14}$

No ano de 2009, foi criado pelo então prefeito Fernando Pimentel ${ }^{15}$ o Programa Vila Viva, trazendo em sua concepção o objetivo (evolucionista) explícito de transformar a favela em vila (através de sua urbanização) e, depois, em bairro (através da regularização fundiária). Entretanto, os movimentos sociais têm denunciado o uso indevido do Programa, com grandes investimentos focados em obras de integração viária e mínimo investimento na real melhoria das comunidades atingidas.

Conforme "Manifesto Vila Viva ou Vila Morta?", o programa vem realizando a "desfavelização forçada", "orientada pelo interesse do capital imobiliário", prevalecendo "a lógica da exclusão urbana levada às últimas consequências pela Prefeitura de Belo Horizonte" (Movimentos Populares, 2008, p. 1). A crítica vem principalmente do fato de que estão sendo retiradas das comunidades muitas famílias, das quais apenas pequena parte é reassentada no próprio local e, ainda assim, em unidades verticais com duvidoso padrão habitacional e tipologia inadequada para a reprodução da família (impossibilidade de expansão) e de sua subsistência (impossibilidade de realização de atividade produtiva ou para consumo alimentar próprio). ${ }^{16}$

À maioria dos removidos, tendo recebido indenizações insuficientes para adquirir imóveis impactados pela especulação imobiliária, resta a compra de casas em regiões distantes do centro, em municípios na periferia da Região Metropolitana de Belo Horizonte, sem infraestrutura adequada e longe das fontes de trabalho e de renda. Ao contrário da filosofia original das intervenções estruturais, que deram origem aos PGEs e mesmo ao Programa Vila Viva, os movimentos apontam que a favela não é pensada como um todo integrado para o benefício de seus cidadãos. Ao contrário, na era do "desfavelamento de novo tipo" (Lopes, 2010), a favela agora é uma área que atrapalha a cidade e está no caminho do desenvolvimento, sendo necessário, portanto, ser removida como qualquer outro entrave à modernização.

Nesse sentido, é importante questionar se está havendo um retrocesso em Belo 
Horizonte, que lança por terra as lutas de décadas, as conquistas e os avanços dos movimentos sociais, ou, simplesmente, se a Lei do Profavela e as intervenções estruturais não foram, ao contrário, um pequeno hiato temporal na prática remocionista e higienista que se mantém na cidade.

\section{As duas inflexões no caso de Belo Horizonte: garantia de permanência e garantia de participaçãao}

Não será possível, no âmbito deste artigo, concluir se afinal o que está havendo é um retrocesso ou apenas a retomada das tradicionais práticas remocionistas e higienistas na cidade, informadas e sustentadas por novos discursos. 0 fato é que houve uma inflexão nas políticas públicas para as favelas, que deve ser apontada.

Ao final, entende-se que tem sido perdido 0 direito à cidade, nos termos de Lefebvre (2001), entendido não apenas como o direito de acesso à infraestrutura e aos serviços urbanos, mas antes, e principalmente, como o direito à vida urbana, à centralidade renovada, aos locais de encontro e trocas, à festa, ao poder, à riqueza, ao uso pleno e inteiro do espaço urbano e à tomada de decisões. Nessa perspectiva, percebe-se um significativo hiato entre o conceito de direito à cidade e sua efetivação.

A inflexão percebida em Belo Horizonte - e que também é sentida em outras partes do País - parece ter dois elementos centrais. Os moradores das favelas têm perdido duas garantias ao mesmo tempo: a garantia (direito) de permanência em seus locais de moradia e a garantia (direito) de participação na tomada de decisões que lhes afetam diretamente. A seguir cada uma dessas inflexões será discutida.

\section{Direito à moradia e garantia de permanência}

Em primeiro lugar, faz-se necessário refletir que, de fato, tanto no Brasil quanto em escala mundial, as práticas remocionistas não foram totalmente eliminadas, em nome de uma suposta tendência urbanizadora das comunidades periféricas. 0 que se vê é que ambas as posturas são conviventes no tempo e mesmo no espaço e se alternam, de acordo com os interesses da hora e da vez.

Ao que tudo indica, a situação vivida atualmente em Belo Horizonte não é um caso isolado. Ao contrário, desde o anúncio de que o País seria sede da Copa do Mundo de 2014 e das Olimpíadas de 2016, várias cidades brasileiras assistiram a uma escalada de remoções em virtude de grandes obras. É importante destacar que tais obras apenas intensificaram um movimento que já vinha sendo sentido anteriormente, não podendo, portanto, ser-lhes atribuída responsabilidade exclusiva.

Na declaração "O que é a Favela Afinal?", fruto de seminário conduzido pelo Observatório de Favelas do Rio de Janeiro (2009), a fragilidade das favelas e de seus moradores na garantia de seus direitos aparece em mais de uma passagem; é vista como território onde as políticas e as ações do Estado são incompletas, a soberania da população é baixa e os direitos sociais não são efetivados. 
A regularização fundiária tem sido apontada por diversos autores como um dos elementos mais importantes na garantia do direito de permanência das famílias moradoras de favelas. Em seu oposto, a falta de garantia legal da propriedade tem facilitado a violação dos direitos dos moradores e aumentado sua vulnerabilidade quando sob ameaça de remoção.

Conforme bem apontam Fernandes e Pereira (2010), no caso de Belo Horizonte tem havido dois graves movimentos. De um lado, a precariedade dos processos de regularização fundiária, que até o momento atingiram número pequeno de famílias beneficiadas, agravando a insegurança com relação à posse da terra e à permanência no local. $E$, de outro, a visão arcaica, restritiva e arbitrária da Prefeitura de Belo Horizonte, agravada pela utilização de recursos do Programa de Aceleração do Crescimento - PAC para a urbanização de favelas, com uma visão remocionista, impactando gravemente as comunidades (notadamente da zona sul e áreas centrais) e contribuindo para os processos de expulsão velada e gentrificação na cidade.

De fato, a expulsão dos pobres das áreas "nobres", até então desconsideradas pelo capital imobiliário, tem sido processo constante e que vem se intensificando no Brasil, apoiada pela ação dos poderes públicos. ${ }^{17}$ Os principais argumentos para a remoção das favelas têm sido para implantação de melhorias urbanas, integração viária, favorecimento da convivência na cidade com a implantação de parques lineares e áreas de lazer, benefício coletivo, o bem comum, etc.

Nesse processo, grandes impactos vêm sendo gerados e desconsiderados, do ponto de vista tanto social quanto urbano e mesmo econômico. Entre diversos outros, citam-se como impactos da remoção de famílias:

- do ponto de vista social: desagregação das relações de parentesco e vizinhança e, consequentemente, dos mecanismos de proteção social contra as principais vulnerabilidades das famílias (inclusive a segurança);

- do ponto de vista urbano: sobrecarga das redes de abastecimento de água, esgotamento sanitário, drenagem e energia elétrica nos locais de destino; impactos sobre 0 atendimento já precário dos serviços de transporte e mobilidade urbana, saúde e educação, entre outros;

- do ponto de vista econômico: desestruturação das alternativas de empregabilidade das famílias, notadamente a proximidade com os locais de emprego; aumento dos custos de deslocamento e, consequentemente, redução das chances de empregabilidade e aumento do desemprego.

Em suma, tem-se, como resultado, a ampliação da segregação social no espaço urbano, uma vez que são adotados como padrão de implantação os grandes conjuntos habitacionais distantes das áreas centrais, modelo este que já mostrou sua precariedade em outras experiências (por exemplo: Cidade de Deus - Rio de Janeiro; Cingapura - São Paulo).

No caso das favelas de Belo Horizonte, 0 mesmo processo tem sido levado a cabo pelo Programa Vila Viva, afetando negativamente as famílias removidas, tanto as que recebem indenizações e vão cada vez mais para longe quanto as que ficam nos prédios construídos na própria comunidade. À expulsão pelo mercado soma-se a expulsão pelo Estado. Os moradores têm perdido seus direitos diante de uma interpretação da lei que os considera "ocupantes 
de má-fé" (ver Fernandes, 2008 e Fernandes e Pereira, 2010).

De acordo com Davis (2006), em todo o mundo há processos em andamento de remoção dos "entraves humanos", e as práticas remocionistas continuam acontecendo em escala global e ampliadas em todo o Terceiro Mundo. "Em consequência, os pobres urbanos são nômades, 'moradores transitórios num estado perpétuo de realocação'" (ibid., p. 106). Em paralelo, vem sendo registrado o crescimento das áreas de pobreza urbana em todo o mundo, levando a perspectivas de um futuro preocupante para as megacidades:

[...] em vez de feitas de vidro e aço, como fora previsto por gerações anteriores de urbanistas, serão construídas em grande parte de tijolo aparente, palha, plástico reciclado, blocos de cimento e restos de madeira. Em vez das cidades de luz arrojando-se aos céus, boa parte do mundo urbano do século XXI instala-se na miséria, cercada de poluição, excrementos e deterioração. Na verdade, o bilhão de habitantes urbanos que moram nas favelas pós-modernas pode mesmo olhar com inveja as ruínas das robustas casas de barro de Çatal Huyuk, na Anatólia, construída no alvorecer da vida urbana há 9 mil anos. (Ibid., pp. 28-29)

Ainda que a situação das favelas brasileiras não seja tão alarmante, em sua maioria, como as estudadas pelo autor na África, Ásia e partes da América Latina, por exemplo, também vem apresentando crescimento desordenado e, em consequência, perda da qualidade de vida em alguns locais, conquistada a duras penas. No caso brasileiro, estudos do final da década de 1990 (ver, por exemplo, PBH/ Ceurb/UFMG, 1999) indicaram processo de aumento no número de favelas e áreas ocupadas, bem como, e principalmente, de adensamento das áreas já existentes, aumentando-se o número de famílias e de pessoas residentes nesses locais.

Entre 2000 e 2010, por outro lado, relatório da ONU-Habitat (2010) aponta que houve mudanças relevantes, no sentido de melhoria das condições de vida nas favelas em todo o mundo, o que indicaria que "os governos conseguiram superar de forma coletiva a Meta 7 do Objetivo de Desenvolvimento do Milênio em pelo menos 2,2 vezes e 10 anos antes de 2020, o prazo final estabelecido" (p. 6). Tal melhoria, entretanto, não foi suficiente para conter o avanço demográfico em tais territórios informais, que tiveram sua população ampliada de 776,7 milhões em 2000 para 827,6 milhões em 2010. Conforme o citado relatório, "os esforços para reduzir o número de moradores de favelas não são nem satisfatórios nem adequados" (p. 10).

Apesar de os estudos indicarem a tendência de crescimento do número absoluto de moradores em favelas no mundo, ${ }^{18}$ no caso brasileiro foi registrado decréscimo na população favelada na última década, em termos tanto percentuais $(10,38 \%$ em relação à população total) quanto absolutos (cerca de 3 milhões de pessoas a menos morando em favelas). Tal mudança é atribuída à implantação de políticas sociais, econômicas, urbanas e habitacionais nos governos Lula (PT - 2002-2010) e Dilma (PT - 2011-2016), em paralelo à redução das taxas de natalidade e migração rural-urbano.

Também em Belo Horizonte os dados da PBH apontam um decréscimo no número de favelas e de seus moradores. Entretanto, a hipótese aqui é que tal redução está condicionada 
não apenas pelos motivos acima apontados no caso brasileiro, mas também, e principalmente, por um contínuo e intenso processo de remoção de famílias e de políticas de desfavelização.

Segundo dados oficiais da Urbel/PBH, em 2002 a cidade tinha 232 vilas, favelas e conjuntos habitacionais implantados pela $\mathrm{PBH}$ (incluindo Zeis 1 e Zeis 3), com 498.656 pessoas residentes em 121.132 domicílios, o que correspondia a $22 \%$ dos habitantes da Capital. Já os dados para 2012 apontam que são 215 áreas (17 a menos), 451 mil habitantes (47 mil a menos) e apenas 19\% do total da cidade. Em que possam pesar diferenças de metodologia para apurar o número total de habitantes nas favelas, não é possível mais negar que o desfavelamento causou impacto e tem sido usado como instrumento da política pública na Capital.

Se, por um lado, houve avanços, no restante do País e em Belo Horizonte, no que se refere à consolidação urbanística das áreas de favelas, ao provimento de infraestrutura urbana, ao saneamento e aos serviços públicos; por outro, "[...] o item no qual menos se avançou foi justamente o que coloca em questão a presença da favela nas cidades, a apropriação e uso do espaço urbano em seu conjunto como direito social" (Observatório de Favelas, 2009, p. 16).

Finalizando esta discussão, é fundamental lembrar que tanto a Constituição Federal de 1988 quanto o Estatuto da Cidade, aprovado em 2001, incluem o direito à moradia como um dos direitos fundamentais, buscando-se, ademais, a garantia da efetivação da função social da terra urbana. Nesse sentido, Fernandes (2008) aponta que há um embate de décadas no Brasil entre dois paradigmas jurídicos: de um lado, o legalismo liberal, hegemônico, individualista, mercantilista e patrimonialista; e, de outro, movimentos que afirmam o direito à cidade e a função social da propriedade. No presente momento do pêndulo das políticas públicas na cidade, a visão legalista e patrimonialista tem triunfado.

\section{Direito à tomada de decisões e participação cidadã}

Quanto à segunda inflexão percebida em Belo Horizonte, relacionada ao direito à participação dos moradores nas decisões que lhes afetam diretamente, o que se tem visto, segundo apontado pelo movimento popular, é a completa falta de diálogo e de respeito às demandas dos moradores. Muitas vezes a população é somente chamada para validar decisões que já foram tomadas, sem consulta prévia ou consideração de suas prioridades ou sugestões.

Alguns autores avaliam que as próprias regras da democracia representativa contribuem muitas vezes para inibir a participação real dos cidadãos nos governos e nas políticas públicas. ${ }^{19}$ Seja pela apropriação do Estado pelo poder econômico e/ou pelas elites, seja pelo esvaziamento do próprio sentido da coisa pública, vê-se muitas vezes o afastamento de indivíduos e grupos sociais das esferas de decisão e de poder coletivo. Para Daniel (1988), no Brasil o esvaziamento da participação na tomada de decisões não é recente, ao contrário, visto que os governos militares, através das restrições à liberdade de expressão e de associação, levaram à despolitização da sociedade e transformaram o próprio Estado em instância puramente administrativa. 
A Constituição Brasileira de 1988 buscou reverter o afastamento da população do fazer político e introduziu, em seu artigo primeiro, o modelo que mescla representação e ação direta do cidadão, fortalecendo os movimentos sociais e ampliando os espaços de participação. Entretanto, ainda que as instâncias de participação tenham sido ampliadas, não há consenso e garantias de que a democracia participativa predomine e caminhe rumo a maior autonomia da população. ${ }^{20}$ Nesse sentido, vê-se a descaracterização de processos participativos, cooptação, esvaziamento e desqualificação das competências das populações na tomada de decisões. Além disso, há uma recusa formal de partes da população em participar do jogo político e de suas regras, o que se traduz no absenteísmo às eleições, ${ }^{21}$ no repúdio público, nos meios de comunicação, às instâncias de representação e nas práticas de mobilização coletiva via redes sociais e tomada das ruas pelos movimentos (organizados ou não).

Outro processo é o escalonamento na capacidade de influenciar decisões, condicionado à estratificação socioespacial. Para Santos Júnior (2008), a segregação espacial nas cidades (fruto da desigualdade) é fator determinante para a segregação da participação, fragilização do tecido associativo e, finalmente, para a "repartição do espaço político brasileiro entre hipercidadãos e subcidadãos" (Santos Júnior, 2008 , p. 150). Apesar de crítico quanto à supervalorização dos planos diretores como instrumentos de mudança, considera que os mecanismos de planejamento trouxeram ganhos, como a incorporação das demandas populares na agenda de discussão; a instauração de uma nova concepção de planejamento, focado na participação popular; e a criação de instâncias participativas. Entretanto, na prática, ainda predominam os interesses das elites e dos setores médios na elaboração dos planos, com baixa participação dos setores populares, que não conseguem contemplar suas demandas nas agendas da política urbana.

No caso de Belo Horizonte, a participação direta foi sendo gradativamente substituída pelas decisões colegiadas, através dos conselhos de políticas públicas, bem como por mecanismos de consulta pontual à população, notadamente o Orçamento Participativo - OP e o OP digital. Mesmo nos casos em que se espera a participação direta do cidadão, como o das conferências e dos fóruns, não há um trabalho prévio de informação e instrumentalização da população para que possa se apropriar dos conteúdos e processos e exercer de forma autônoma seu direito à voz e ao voto.

0 que se vê é a incorporação do discurso da participação em todas as esferas, sem significar verdadeiramente um caminho rumo à emancipação do cidadão como sujeito de direitos. 0 Plano Plurianual de Ação Governamental - PPAG 2014-201722 reafirma a supremacia da participação no planejamento da cidade, realçando que essa é (ou deveria ser) a base de todas as ações desenvolvidas pela administração municipal. ${ }^{23}$

Realça-se, ainda, que alguns mecanismos considerados como exemplos bem-sucedidos de incorporação de demandas da população através da participação direta apresentaram redução de sua importância em Belo Horizonte nos últimos anos. Exemplo é o Orçamento Participativo, implantado em 1993 na administração de Patrus Ananias, ${ }^{24}$ que vem sofrendo críticas, entre elas: a excessiva tecnicização e burocratização dos processos de escolha de prioridades, 
limitando, direcionando e até inviabilizando as demandas da população; a disponibilização de pequeno percentual do orçamento para as decisões via OP (em média 3\% da arrecadação); a morosidade e atrasos na execução das obras; e a criação do OP Digital, esvaziando ainda mais as esferas de participação da comunidade.

Outro processo verificado foi a institucionalização da prática participativa e do controle social, sendo a interferência direta dos cidadãos fortemente direcionada para os conseIhos de políticas públicas, que hoje são 23 na cidade, além dos nove conselhos tutelares, um para cada regional. Avritzer (2010) aponta problemas nas instâncias colegiadas em Belo Horizonte, principalmente: o monopólio da representação (indicação dos membros dos conseIhos por entidades); a predominância de idosos e aposentados (que têm tempo para participar) nos conselhos; a especialização da representação (pessoas que se tornam "profissionais" em serem conselheiros); a baixa intersetorialidade entre os conselhos/políticas; as fragilidades da capacitação dos conselheiros para exercer seu papel; e a falta de estrutura dos conselhos para funcionamento mínimo, entre outros.

No caso das intervenções em favelas, tem-se adotado um modelo consultivo, com a criação de instâncias e de momentos de ouvidoria das demandas da população, sem que se traduza em real poder de decisão dos cidadãos na condução da coisa pública. Ao contrário, são frequentes os embates entre a Prefeitura e a sociedade civil, que tem buscado o apoio e a interferência do Ministério Público para garantir espaços mínimos de discussão e revisão de decisões tomadas unilateralmente pela administração. Mesmo nos casos em que se convocam assembleias, conferências e fóruns de políticas públicas, não há trabalho prévio de informação e instrumentalização da população para que possa se apropriar dos conteúdos e processos e exercer de forma autônoma seu direito à voz e ao voto. Ao final, são tomadas decisões sem se saber em que se está votando, conforme depoimentos dos próprios moradores participantes desses encontros.

Em especial, quando se trata das intervenções urbanas nas comunidades de baixa renda, reafirma-se que houve retrocesso nos últimos anos nos espaços de decisão e participação dos moradores. Ao analisar as obras da Linha Verde, Lopes (2010) mostra que a comunidade não foi consultada nem quanto aos objetivos dos projetos, nem quanto aos meios para atingi-los. De fato, foi feita a mera apresentação de decisões já tomadas para que a população as validasse; uma "participação orientada", direcionada para objetivos do poder público e sem espaço para que se alterassem os rumos do projeto.

Rolnik (2012) aponta situação semelhante ligada aos grandes projetos nas favelas em outros locais do País. Segundo ela,

Finalmente, quando recursos públicos vultosos estão disponíveis para investimentos na urbanização das favelas do país - com o PAC das favelas -, o que se observa é a desconstituição dos processos e fóruns participativos, uma geografia seletiva de favelas a serem urbanizadas e [...] processos massivos de remoção em decorrência da implementação de projetos e obras, muitas vezes com uso da violência. Mais grave ainda é o generalizado não reconhecimento por parte das autoridades municipais - dos juízes, promotores e procuradores envolvidos - da regularização fundiária como um "direito" dos moradores, tratando o tema como 
"questão social" e, portanto, dependente da discricionariedade e, na maior parte dos casos, do não equacionamento desse direito através da implementação de alternativas sustentáveis à remoção. (Rolnik, 2012, p. 92)

Por outro lado, Santos Júnior (2008) é otimista ao constatar que parte importante das lideranças que participam nos conselhos e de outras instâncias formalizadas também integra os movimentos sociais, em suas diversas modalidades de luta e ativismo. Nessa perspectiva, resta uma esperança de que a participação também se construa nas cidades através da ação cotidiana dos cidadãos, para além das instâncias formalizadas e do aparato burocrático e administrativo que acabam por impedir, mais do que favorecer, a inclusão dos pobres na política urbana.

Em Belo Horizonte, tem-se avançado para novas formas de ativismo, através dos recentes movimentos de rua (Jornadas de Junho, 2013), que recolocam no centro das discussões o direito à cidade, à participação e à tomada de decisões. Trazem como estratégia, entre outras, a ocupação dos espaços públicos e o uso da cultura como mote para a retomada da cidadania e da sociabilidade nos espaços urbanos (Libânio, 2015).

Finalizando com Harvey (2013, p. 1), "o direito à cidade é [...] um direito de mudar a nós mesmos, mudando a cidade. Além disso, é um direito coletivo, e não individual [...]".Ao final, espera-se que o direito à cidade signifique, de fato, a capacidade de os indivíduos e de grupos sociais incidirem nas políticas, a efetiva participação nas decisões que lhes afetam diretamente na gestão pública do território. Se o cidadão não nasce, faz-se; é através do exercício da prática política que é possível realizar essa transformação rumo à emancipação social dos indivíduos. Para tanto, além das condições estruturais e legais para o exercício do jogo democrático, é necessário que os diversos atores em convivência na cidade tenham ativos, capitais de diversas ordens que lhes permitam participar e influir nesse jogo, para além dos simulacros de participação vazia e que já não mais convencem ninguém.

\section{Empreendedorismo urbano e a "Nova Belo Horizonte": estado e mercado juntos contra a população e os direitos de cidadania?}

Nesse contexto, é possível afirmar que planejamento urbano no Brasil já nasceu sob a égide do embelezamento e do melhoramento das cidades, sob inspiração do urbanismo europeu (leia-se francês) (Maricato, 2000). Apesar de não ser novidade na vida das cidades o planejamento estruturado sobre os desejos de embelezamento e de civilização das elites, novas tendências vêm se impondo no contexto das cidades mundiais.

Castells e Borja (1996) apontam o protagonismo econômico como uma das principais ferramentas para a sobrevivência das cidades na sociedade globalizada. Para eles, o governo municipal deve ser empreendedor, tomando como norteadores seu planejamento estratégico e o "plano de futuro" para a cidade. Reforçam a tese de que os governos (principalmente em âmbito local) podem (e devem) agir na cidade por conta própria, fazendo eles mesmos - ou 
através de concessão ou associação com a iniciativa privada - grandes obras, empresas mistas, investimentos tecnológicos, etc.

0 protagonismo urbano - a cidade empreendedora - teria principalmente dois objetivos: a) seu posicionamento no mercado mundial, atratividade, competitividade; e b) 0 bem-estar dos cidadãos, gerando maior qualidade de vida. De acordo com os autores, as grandes cidades devem responder a cinco tipos de objetivos: nova base econômica, melhoria da infraestrutura urbana, qualidade de vida, integração social e governabilidade. Somente gerando uma capacidade de resposta a esses propósitos, elas poderão, por um lado, ser competitivas para o exterior e inserir-se nos espaços econômicos globais; e, por outro, dar garantias a sua população de um mínimo de bem-estar para que a convivência democrática possa se consolidar (ibid.).

Os principais desafios seriam no sentido da modernização da infraestrutura urbana, da criação de centralidades e de espaços públicos qualificados e da geração de competitividade econômica. Nesse sentido, os autores apontam a necessidade de mais autonomia municipal; implantação de novas formas de gestão; ação baseada na inovação; reforma política e administrativa.

Em contraponto, Harvey (2006) correlaciona empreendedorismo urbano e empobrecimento. 0 autor discute como o capitalismo, com seus processos econômicos, produz 0 espaço urbano. A urbanização como processo social produz artefatos (formas construídas, espaços produzidos, etc.), arranjos institucionais, sistemas políticos, formas legais, etc. Aponta uma mudança de postura dos governos, de uma visão administrativista das cidades para outra empreendedora.

Para ele, o empreendedorismo urbano tem como pano de fundo as crises econômicas mundiais, bem como a alta mobilidade do capital multinacional, liberto das barreiras espaciais para as decisões locacionais. Nesse panorama, cidades passam a disputar entre si os capitais, empresas e consumidores individuais, oferecendo, cada qual, diferenciais competitivos, inicialmente relacionados a infraestrutura e serviços urbanos, além de benefícios econômicos, fiscais e outros subsídios aos empreendimentos produtivos.

Diferentemente da visão apresentada por Castells e Borja, Harvey afirma que a ênfase no empreendedorismo tem trazido graves consequências (tanto em âmbito macroeconômico quanto territorial e social, por exemplo), entre outras: o desenvolvimento desigual do território; o empobrecimento da população local (criação de uma "subclasse"); a oneração das administrações (poder público assume os riscos e ônus do investimento); e, por fim, a própria instabilidade do sistema urbano.

Em suma, o empreendedorismo urbano traria uma solução temporária e perversa para o crescimento das cidades, em especial porque o próprio processo de competição interurbana acabaria por eliminar seus diferenciais, todas estariam submetidas à mesma lógica da espetacularização e dos fluxos econômicos no capitalismo mundial.

Belo Horizonte não foge a essa lógica do empreendedorismo urbano, ao contrário. Da mesma forma que verificado em outras partes do Brasil e do mundo, a cidade vem perseguindo o embelezamento, a competitividade e 
a visibilidade internacional. No planejamento estratégico e plano de futuro da $\mathrm{PBH}$, base para as diversas políticas públicas, constam seis Objetivos Estratégicos de Longo Prazo, ${ }^{25}$ desafios a serem enfrentados até 2030. ${ }^{26}$ Entre eles, a competitividade na rede mundial de cidades está em primeiro lugar, e, ironicamente, a gestão democrática e participativa e o ambiente social saudável ocupam as duas últimas posições.

Fazem parte dessa visão de cidade empreendedora projetos como a Linha Verde, que liga o centro ao aeroporto de Confins; o Programa Vila Viva, responsável pela abertura de grandes eixos viários dentro das favelas; e a Operação urbana consorciada Nova $\mathrm{BH}$, recentemente questionada pelo Ministério Público. Todos com grande impacto social e remoção de significativo número de famílias de baixa renda dos territórios centrais e mais valorizados. ${ }^{27}$

Os movimentos populares em Belo Horizonte consideram as ações de remoção de famílias levadas a cabo pelo poder público como um processo de agravamento da segregação social na cidade, com a expulsão dos pobres das áreas valorizadas, em benefício do mercado imobiliário. Se remover uma favela pode, segundo estimativas do mercado, valorizar toda uma região de classe média e média-alta em cerca de $30 \%$, não por coincidência os primeiros programas Vila Viva foram implantados no Aglomerado da Serra, Morro das Pedras e Barragem Santa Lúcia, zona sul da Capital. Conforme Manifesto Vila Viva ou Vila Morta?:

As intervenções estão orientadas pelos interesses do capital imobiliário, pois apenas as vilas mais valorizadas da cidade, bem servidas de equipamentos sociais e com excelente localização, como o
Aglomerado da Serra, o Morro das Pedras e a Pedreira Prado Lopes, serão afetadas. Ora, por que as áreas mais distantes da cidade, que apresentam índice de vulnerabilidade social igual ou, muitas vezes, superior aos das vilas predefinidas, não foram contempladas no programa?[...] A verdade é que o esgotamento das áreas edificáveis nas regiões mais valorizadas da cidade chamou a atenção do capital imobiliário para as vilas e favelas, tidas, até então, como capital morto. (Movimentos Populares, 2008, p. 1)

Além da valorização imobiliária, outro resultado da remoção de favelas é a ampliação da sensação de segurança para os moradores de suas áreas vizinhas. Davis (2009), ao analisar Los Angeles, discute o fenômeno do medo nas cidades como indutor de novas formas de convivência urbana e mesmo de configuração espacial. 0 autor mostra como a sociedade contemporânea usa, como mecanismos de exclusão, elementos como o traçado urbano, as soluções arquitetônicas e a semiótica do espaço, através de "sinais invisíveis que impedem a entrada do "Outro" da subclasse" (Davis, 2009, p. 237).

Para manter pobres separados dos ricos, os elementos de separação física (e todo o aparato de repressão acoplado) são precedidos e/ ou justificados por toda uma retórica construída socialmente, baseada no que Davis (2009) chama de Ecologia do Medo. Caldeira (1997), analisando o caso paulista, também reforça essa ideia, segundo a qual o crescimento da violência trouxe consigo mudanças tanto nas formas de morar quanto nos hábitos e no uso coletivo das cidades. A segregação social, nesse âmbito, passa a ser valorizada e reafirmada como símbolo de status. "A construção de 
símbolos de status é um processo que elabora distâncias sociais e cria meios para a afirmação de diferenças e desigualdades sociais" (Caldeira, 1997, p. 159), contribuindo para o desaparecimento da vida coletiva nos espaços públicos. O Plano Estratégico de Belo Horizonte quer "Todas as Vilas Vivas". Quer uma cidade competitiva, bonita e segura. Mesmo que o preço seja a expulsão crescente dos pobres das áreas centrais, seja pelo mercado, seja pela remoção em virtude das obras públicas.

0 destino das comunidades não conta mais, nos dias atuais, com a força do movimento favelado organizado, como na época da luta que culminou com a implantação do Profavela. Hoje, os argumentos do crescimento urbano e da melhoria da qualidade de vida (para quem?) não permitem mais a existência de vozes discordantes. Aos poucos, as favelas vão dando espaço a grandes obras viárias e, junto com a vitória do urbanismo, vão-se as histórias e a cultura das favelas na cidade. Mais um capítulo que se escreve sobre a luta pela ocupação e sobre a resistência à desocupação das favelas de Belo Horizonte.

A temática demanda uma discussão mais aprofundada a respeito das alternativas e dos caminhos que devem ser seguidos para reverter esse quadro perverso em andamento nas cidades brasileiras. Seja o Programa Vila Viva em Belo Horizonte, sejam as UPPs no Rio de Janeiro ou os "cheques-despejo" e incêndios criminosos em São Paulo, fato é que está havendo uma inflexão nas formas de pensar e lidar com as favelas brasileiras, que desconsidera os direitos e as conquistas históricas dos moradores desses territórios. A mobilização e a postura ativa da sociedade civil se fazem urgentes nesse quadro. Finalizando com Fernandes,

É imprescindível que os moradores de vilas e favelas e seus parceiros atuem preventivamente, buscando o reconhecimento dos seus direitos. Outro aspecto importante a ser ressaltado é que a mobilização social tem que ser constante e tem que buscar também a participação nos processos de decisão desde o início da formulação das políticas, e não apenas quando da sua implementação. (2010, p. 195)

Para Vainer (2001), um governo local que, de fato, inclua a participação cidadã e a garantia de direitos em sua atuação e que seja comprometido com os grupos subalternos, deve ter três objetivos centrais: a) a redução das desigualdades e a melhoria das condições materiais e imateriais dos explorados; b) a constituição de sujeitos políticos coletivos, através da organização e da luta popular; e c) a desmontagem dos mecanismos tradicionais de poder, tais como o clientelismo, a corrupção, a troca de favores e a privatização dos recursos públicos.

Nesse panorama, para onde vai Belo Horizonte? Infelizmente, há que se concordar que "Belo Horizonte é um dos exemplos mais contundentes da natureza perversa das relações historicamente estabelecidas no País entre direito, planejamento territorial e mercado imobiliário" (Fernandes, 2010, p. 178). E agora, mais uma vez, ajudado pela administração pública. 


\section{Clarice de Assis Libânio}

Universidade Federal de Minas Gerais, Escola de Arquitetura. Belo Horizonte, MG/Brasil. claricelibanio@gmail.com

\section{Notas}

(1) O conceito de favela tem sido alvo de grandes discussões no Brasil nos últimos anos, visto a significativa multiplicidade e diversidade de territórios urbanos que apresentam características diferenciadas da chamada "cidade formal", seja por sua conformação físico-espacial e pelas formas de ocupação do espaço, seja pela situação fundiária dos terrenos e mesmo pelo perfil socioeconômico de sua população. Para acompanhar tal debate, ver Observatório de Favelas do Rio de Janeiro (2009). No presente artigo, optou-se por utilizar ora o termo favela, ora vila (mais comumente adotado pelos técnicos da administração municipal em Belo Horizonte) para designar aqueles locais que o IBGE classifica como aglomerados subnormais, com suas tipicidades na conformação do território. No caso de Belo Horizonte, tais áreas são distribuídas entre as Zeis - Zonas de especial interesse social - 1 e a Zeis 3, como se verá a seguir.

(2) Tais números incluem as chamadas Zeis - Zonas de Especial Interesse Social, sendo a Zeis 1 relativa às áreas de favelas ou ocupação ilegal e a Zeis 3 relativa às habitações de baixa renda construídas pela municipalidade, seja para suprir o déficit habitacional de Belo Horizonte, seja para realocar famílias removidas de projetos e grandes obras urbanas. No presente trabalho, está-se tratando de ambos os tipos de territórios, ainda que a vulnerabilidade na Zeis 1 seja maior, pela insegurança da posse da terra.

(3) Ver dados em www.favelaeissoai.com.br.

(4) Sobre o surgimento das primeiras favelas e políticas públicas no Rio de Janeiro, ver Silva (2005) e Zaluar (2004).

(5) Sobre o déficit habitacional no Brasil, ver Fundação João Pinheiro (2015). A nova metodologia adotada inclui o déficit habitacional stricto sensu (habitação precária - domicílios rústicos e domicílios improvisados -, coabitação familiar - famílias conviventes ou cômodos -, ônus excessivo com aluguel urbano e adensamento excessivo de domicílios alugados) e o déficit habitacional relativo (domicílios com carência de infraestrutura - energia elétrica, água, esgotamento sanitário, banheiro exclusivo -, adensamento excessivo de domicílios próprios, ausência de banheiro exclusivo, cobertura inadequada ou inadequação fundiária). Em Belo Horizonte, o déficit, em 2012, era de 136.641 moradias, das quais $8,2 \%$ de déficit relativo. A grande maioria delas está situada na faixa de renda de 0 a 3 salários mínimos $(76,1 \%)$. Por outro lado, há no município cerca de 132.284 domicílios vagos em condições de serem ocupados, um estoque de moradias muitas vezes destinado à especulação imobiliária ou inadequado para as faixas de renda em que o déficit habitacional é maior.

(6) Administração Celso Mello de Azevedo, coligação UDN-PR-PDC-PTN-PL, 1955-1959.

(7) Administração Oswaldo Pieruccetti, prefeito designado por Magalhães Pinto, 1971-1975. 
(8) A lei do Profavela reconhecia as favelas instaladas no município até 1980 como áreas especiais de zoneamento - Setor Especial 4 (SE-4), que deveriam 1) ter legislação específica; 2) ser urbanizadas respeitando a tipicidade da ocupação local e 3) receber processos de regularização fundiária, cabendo ao Estado transferir para os moradores a propriedade da terra.

(9) Entre 1983 e dezembro de 1985, três prefeitos sucederam-se à frente da administração municipal: Hélio Garcia, Antônio Carlos Carone e Rui Lage. Em 1986 foi eleito Sérgio Mário Ferrara - PMDB, 1986-1988.

(10) Gestões Pimenta da Veiga - PSDB, 1989-1990 e Eduardo Azeredo - PSDB, 1990-1992.

(11) Administrações Patrus Ananias - PT, 1993-1996 e Célio de Castro - PSB, 1997-2002.

(12) Período que inclui parte da administração Fernando Pimentel - PT, 2002/2004; 2005-2008 e toda a gestão de Márcio Lacerda - PSB, 2009-2016.

(13) Um exemplo recente é a Linha Verde, que liga o centro de Belo Horizonte ao aeroporto de Confins. Levada a cabo em convênio entre DER, Codemig / Governo do Estado e Prefeitura de Belo Horizonte, a Linha Verde foi responsável por remover do mapa da cidade as vilas São Paulo/Modelo, Carioca, Real, Maria Virgínia e São Miguel/Vietnã, além de grande parte da vila Suzana I, situadas na confluência das regionais Nordeste e Pampulha, Belo Horizonte.

(14) Apenas a obra da Linha Verde, sozinha, foi responsável pela remoção de cerca de 1.000 famílias entre 2006 e 2007.

(15) PT, 2002-2008.

(16) Atualmente as unidades habitacionais construídas para reassentamento têm se enquadrado no Programa Minha Casa, Minha Vida, sobre o qual não será possível discorrer neste artigo, mas que tem sido alvo de inúmeras críticas pelo modelo adotado - urbanístico, financeiro, arquitetônico - e seus impactos sociais negativos significativos (ver, por exemplo, Cardoso e Aragão, 2012).

(17) Ainda que os dados sobre a valorização imobiliária em Belo Horizonte sejam de difícil mensuração, pela precariedade e limitação de acesso às fontes - o próprio capital imobiliário e seus agentes -, pesquisas informais e consulta a publicações em jornais locais apontam que a proximidade com uma favela pode depreciar um imóvel da zona sul de Belo Horizonte em cerca de $30 \%$. Nessa perspectiva, não seria de se estranhar o fato de que as maiores intervenções do Vila Viva estão justamente localizadas na zona sul da Capital, onde bairros "nobres" fazem fronteira com as favelas.

(18) Ver Davis (2006), Maricato (2006) e ONU-Habitat (2010).

(19) Ver, por exemplo, Santos (2002), Souza (2010) e Daniel (1988).

(20) Exemplo recente foi a não aprovação, no Congresso Nacional, da Política Nacional de Participação Social e do Sistema Nacional de Participação Social - decreto 8.243, de 23/5/2014, que propunha ampliar e fortalecer os mecanismos e instâncias de participação direta da população no Estado, nos mesmos moldes institucionalizados que já ocorrem.

(21) Nas eleições presidenciais de 2014 , a abstenção média foi de $20 \%$ entre os dois turnos, cerca de 30 milhões de eleitores.

(22) Administração Márcio Lacerda - PSB, 2009-2016. 
(23) “Belo Horizonte é a cidade das organizações comunitárias, dos movimentos de base e de anistia, dos movimentos de moradia e de saúde, das diversas expressões culturais e das novas tecnologias, enfim, é também a cidade de territorialidades solidárias, sociais e políticas. São referências que orientam a prática de gestão social, urbana e econômica da cidade, a participação popular, a democratização das relações de poder, a descentralização dos serviços, a inversão de prioridade na alocação de recursos públicos, o investimento na qualidade do espaço urbano, com suas dimensões sociais e ambientais, e o fomento, apoio e legitimação das práticas de organização popular e controle social” (PBH, 2013, p. 10).

(24) PT, 1993-1996.

(25) São eles: “I) Multiplicar oportunidades de trabalho e promover ambiente favorável à criação e ao desenvolvimento de negócios, impulsionados por serviços de valor agregado, capital humano qualificado e inserção competitiva nas redes nacional e mundial de cidades; II) buscar qualidade de vida para todos, sustentada na eficiente organização do espaço urbano e em redes colaborativas de serviços que se estendem pela região metropolitana; III) promover a sustentabilidade ambiental, resultante da universalização do saneamento básico, da preservação de áreas verdes, da recuperação de áreas degradadas, da redução das emissões de poluentes, da eficiência energética e da boa capacidade de prevenção, mitigação e adaptação diante de ocorrências adversas de grande escala; IV) assegurar as melhores condições de mobilidade, acessibilidade e conectividade em todo o espaço urbano e contribuir para a sua melhoria em âmbito metropolitano; V) consolidar ambiente político-institucional de qualidade, baseado na integração metropolitana e em gestão pública democrática e participativa; e VI) propiciar ambiente social que estimule a convivência alegre e saudável entre as pessoas". (PBH, 2013, p.11).

(26) Administração Márcio Lacerda - PSB, 2009-2016.

(27) Para o período 2014-2017, a estimativa é de 6.000 novas remoções nas favelas em virtude de tais programas, excluídas as 8.000 famílias que ocuparam a região da Isidora e estão sob ameaça constante de retirada por força policial.

\section{Referências}

AVRITZER, L. (2010). Repensando os mecanismos participativos de Belo Horizonte: representação, capacitação e intersetorialidade. Relatório final do Projeto Democracia Participativa - Proep. Belo Horizonte.

CALDEIRA, T. P. R. (1997). Enclaves fortificados: a nova segregação urbana. Novos Estudos Cebrap, n. 47, pp. 179-192.

CARDOSO, A. L. e ARAGÃO, T. A. (2012). Reestruturação do setor imobiliário e o papel do Programa Minha Casa Minha Vida. In: XII SEMINÁRIO DA REDE IBEROAMERICANA DE PESQUISADORES SOBRE GLOBALIZAÇÃO E TERRITÓRIO (RII). Belo Horizonte. Anais. Disponível em: http://www.rii. sei.ba.gov.br/anais/g4/restruturacao\%20do\%20setor\%20imobiliario\%20e\%20o\%20papel\%20 do\%20programa\%20minha\%20casa\%20minha\%20vida.pdf. Acesso em: 27 ago 2013. 
CASTELLS, M. e BORJA, J. (1996) As cidades como atores políticos. Novos Estudos. São Paulo, n. 45, pp. 152-166. Disponível em: http://www.acsmce.com.br/wp-content/uploads/2012/10/ASCIDADES-COMO-ATORES-POL\%C3\%8DTICOS.pdf. Acesso em: 25 ago 2013.

DANIEL, C. (1988). Poder local no Brasil urbano. Espaço \& Debates, n. 24, pp. 26-39.

DAVIS, M. (2006). Planeta favela. São Paulo, Boitempo.

(2009). Cidade de Quartzo: escavando o futuro em Los Angeles. São Paulo, Boitempo.

FERNANDES, E. e PEREIRA, H. D. (2010). Legalização das favelas: qual é o problema de Belo Horizonte? Planejamento e Políticas Públicas, n. 34, pp. 171-199.

FERNANDES, E. (2008). "Reforma urbana e reforma jurídica no Brasil: duas questões para reflexão". In: COSTA, G. M. e MENDONÇA, J. Planejamento urbano no Brasil: trajetória e perspectivas. Belo Horizonte, Ed. C/Arte, pp. 123-135.

FUNDAÇÃO JOÃO PINHEIRO (2015). Centro de Estatística e Informações. Déficit habitacional no Brasil 2011-2012 / Fundação João Pinheiro. Centro de Estatística e Informações - Belo Horizonte. Disponível em: http://www.fjp.mg.gov.br/index.php/docman/cei/559-deficithabitacional-2011-2012/file. Acesso em: 18 ago 2016.

HARVEY, D. (2006). “Do Administrativismo ao Empreendedorismo: a transformação da governança urbana no capitalismo tardio". In: HARVEY, D. A produção capitalista do espaço. São Paulo, Annablume, pp. 163-190. Disponível em: http://www.mom.arq.ufmg.br/mom/babel/textos/ harvey-producao-capitalista-espaco.pdf. Acesso em: 25 ago 2013.

(2013). O direito à cidade. Revista Piauí n. 82. Disponível em: http://revistapiaui.estadao.com. br/edicao-82/tribuna-livre-da-luta-de-classes/o-direito-a-cidade.

INSTITUTO BRASILEIRO DE GEOGRAFIA E ESTATÍSTICA - IBGE (2013). Censo Demográfico 2010. Aglomerados Subnormais. Informações territoriais. Rio de Janeiro. Disponível em: http:// biblioteca.ibge.gov.br/biblioteca-catalogo?view=detalhes\&id=7552. Acesso em: 18 ago 2016.

LEFEBVRE, H. (2001). O direito à cidade. São Paulo, Centauro.

LIBÂNIO, C. A. (2007). "Um século de favela: do Bom Selvagem ao Abusado". In: Pensando as favelas de Belo Horizonte - ensaios. Belo Horizonte, Favela é Isso Aí (Coleção Prosa e Poesia no Morro).

(2015). Democracia, participação e direito à cidade: um olhar sobre o jogo, suas regras e as possibilidades de emancipação. In: ENCONTRO NACIONAL DA ASSOCIAÇÃO NACIONAL DE PÓSGRADUAÇÃO EM PESQUISA EM PLANEJAMENTO URBANO E REGIONAL. Belo Horizonte, MG. Anais. Belo Horizonte, Anpur.

LOPES, E. (2010). O Projeto Linha Verde e a remoção de cinco vilas: um estudo de caso da prática do desfavelamento de novo tipo no espaço urbano de Belo Horizonte. Dissertação de Mestrado. Belo Horizonte, Universidade Federal de Minas Gerais. Belo Horizonte. Disponível em: http://www. bibliotecadigital.ufmg.br/dspace/bitstream/handle/1843/MPBB-8AWDPV/disserta__o_erika_ lopes.pdf?sequence=1. Acesso em: 30 nov 2013.

MARICATO, E. (2000). "As ideias fora do lugar e o lugar fora das ideias - Planejamento Urbano no Brasil". In: ARANTES, O.; VAINER, C. e MARICATO, E. A cidade do pensamento único: desmanchando consensos. Petrópolis, Vozes. Disponível em: http://www.ub.edu/escult/doctorat/html/ lecturas/a_ciudade_do_pensamento_unico.pdf. Acesso em: 25 ago 2013. 
MARICATO, E. (2006). “Um mundo dominado pelas favelas”. In: DAVIS, M. Planeta Favela. São Paulo, Boitempo.

(2007). Nunca fomos tão participativos. Disponível em: http://www.observatoriodasmetropoles.ufrj. br/artigo_boletim-020.htm. Acesso em: 3 dez 2013.

(2011). O impasse da política urbana no Brasil. Petrópolis, Vozes.

MOVIMENTOS POPULARES (2008). BH - Programa Vila-Viva ou Vila-Morta? Disponível em: http:// www.midiaindependente.org/pt/blue/2008/10/429697.shtml. Acesso em: 20 nov 2013.

OBSERVATÓRIO DE FAVELAS DO RIO DE JANEIRO (2009). O que é a favela afinal? Rio de Janeiro, Observatório de Favelas do Rio de Janeiro.

ONU-HABITAT (2010). Estado das Cidades do Mundo 2010/2011: Unindo o Urbano Dividido. Resumo e principais constatações. Rio de Janeiro, Instituto de Pesquisa Econômica Aplicada-Ipea. Disponível em: http://www.ipea.gov.br/agencia/images/stories/PDFs/100408_cidadesdomundo_ portugues.pdf. Acesso em: 18 ago 2016.

PBH / CEURB - UFMG (1999). Plano Estratégico de Diretrizes e Intervenções para Zonas de Especial Interesse Social (Planão). Belo Horizonte.

PBH. Secretaria Municipal de Planejamento, Orçamento e Informação (2013). PPAG. Plano Plurianual de Ação Governamental 2014-2017. Disponível em: http://portalpbh.pbh.gov.br/pbh/ecp/ comunidade.do?evento=portlet\&pldPIc=ecpTaxonomiaMenuPortal\&app=contaspublicas\&tax= 36659\&lang=pt_BR\&pg=6420\&taxp=0\&. Acesso em: 15 nov 2013.

ROLNIK, R. (2012). "Dez anos do Estatuto da Cidade: das lutas pela reforma urbana às cidades da copa do mundo". In: RIBEIRO, A. C. T.; VAZ, L. V. e SILVA, M. L. P. (orgs.). Leituras da Cidade. Rio de Janeiro, Anpur, Letra Capital. Disponível em: https://raquelrolnik.files.wordpress. com/2013/07/10-anos-do-estatuto-da-cidade.pdf. Acesso em 18 ago 2016.

SANTOS, B. S. (2002). Democratizar a democracia: os caminhos da democracia participativa. Rio de Janeiro, Civilização Brasileira.

SANTOS JUNIOR, O. A. (2008). "Reforma Urbana: desafios para o planejamento como práxis transformadora", In: COSTA, G. M. e MENDONÇA, J. Planejamento urbano no Brasil: trajetória e perspectivas. Belo Horizonte, Ed. C/Arte.

SILVA, J. de S. e (2005). Favela, alegria e dor na cidade. Rio de Janeiro, Editora Senac Rio.

SOUZA, M. L. de (2010). Mudar a cidade: uma introdução crítica ao planejamento e gestão urbanos. Rio de Janeiro, Bertrand Brasil.

Texto recebido em 14/jan/2016

Texto aprovado em 31/mar/2016 